\title{
Closing the Sustainable Life Cycle Loop of Membrane Technology via a Cellulose Biomass Platform
}

\author{
Hai Yen Nguyen Thi, Sumin Kim, Bao Tran Duy Nguyen, Daseul Lim, Sushil Kumar, Hoik Lee,* \\ Gyorgy Szekely,* and Jeong F. Kim*
}

Cite This: https://doi.org/10.1021/acssuschemeng.1c08554

Read Online

\begin{tabular}{|c|c|c|}
\hline & 山 Metrics \& More & 回 Article Recommendations \\
\hline
\end{tabular}

ABSTRACT: Membrane technology has become an indispensable part of our daily lives. The rapid growth of membrane technology has been breeding an unavoidable yet critical challenge-the unsustainable disposal of used membranes. Commercial polymer membranes are fabricated from fossil-based monomers and polymers that are not biodegradable. Hence, there is an urgent need to develop membranes that are sustainable from cradle to grave, i.e., both bioderived and biodegradable. Cellulose is one of the most abundant biopolymers that are biodegradable upon disposal. However, it is only soluble in a handful of solvents, limiting its fabrication into membranes at an industrial scale. To circumvent this bottleneck, in this work, we propose a sustainable and scalable method to fabricate cellulose membranes from cellulose acetate with a sacrificial acetate group. The proposed method allows cellulose membrane fabrication utilizing green solvents, and the fabrication procedure is sustainable with minimal solvent consumption. One of the most appealing applications of cellulose membranes is organic solvent nanofiltration (OSN). It is an emerging technology to separate solutes in nanoprecision in harsh organic solvents, requiring solvent-stable materials. Surprisingly, the cellulose membranes exhibited unique transport behaviors, with solute rejection ranging from 100 to $-100 \%$ depending on the solvent medium. Such trends were not previously observed in the OSN literature, and the underlying mechanism was thoroughly investigated. Importantly, the membranes were completely biodegradable in a carbon-neutral manner upon disposal. The life cycle of cellulose membranes was compared with that of conventional OSN membranes in a qualitative and comparative study. The proposed methodology can be applied to substitute fossil-based polymers in all aspects of membrane technology, and it has the potential to become a sustainable fabrication platform for membrane materials.

KEYWORDS: cellulose, solvent resistance, membrane technology, organic solvent nanofiltration, green solvents, biodegradability

\section{INTRODUCTION}

The recent outbreak of coronavirus disease 2019 (COVID-19) pandemic in 2020 has resulted in an explosion of demand for mask air filters to an $\$ 80$ billion annual market. ${ }^{1}$ It has been estimated that an astounding 129 billion face masks are worn and discarded globally every month. ${ }^{2}$ Apart from the mask filter application, the membrane technology has become an indispensable tool in many industries including battery separators, fuel cell and electrolysis systems, ${ }^{3-5}$ hemodialysis and artificial lungs, ${ }^{6}$ and water treatment and chemical separations. $^{5,7-9}$

Such rapid growth of membrane markets inevitably exacerbates the challenges of disposed polymer membrane waste. Currently, most of the membranes are fabricated from fossil-based polymers, including polyethylene (PE), polypropylene (PP), polysulfone (PSf), poly(vinylidene fluoride) (PVDF), polyimide (PI), and poly(benzimidazole) (PBI), among others. The previous study has indicated that about $12 \%$ of all polymers get incinerated after use (hence releasing
$\mathrm{CO}_{2}$ ), and $80 \%$ end up in landfills, which eventually find their way into the ocean. ${ }^{10}$

Although membranes prepared from these polymers exhibit excellent performance, these fossil-based polymers do not biodegrade $^{11,12}$ and can break apart into microplastics. ${ }^{13,14}$ These microplastics are ingested by living organisms in the ocean, and they make their way up the food chain to the foods we consume. Certainly, these microplastics are adversely impacting the environment and other species although their potential hazardous effects to humans are yet unknown. ${ }^{14}$

As a result, there is a strong consensus that fossil-based polymers, although enormously beneficial to mankind, must be hastily substituted with bioderived and biodegradable poly-

Received: December 21, 2021

Revised: January 28, 2022 


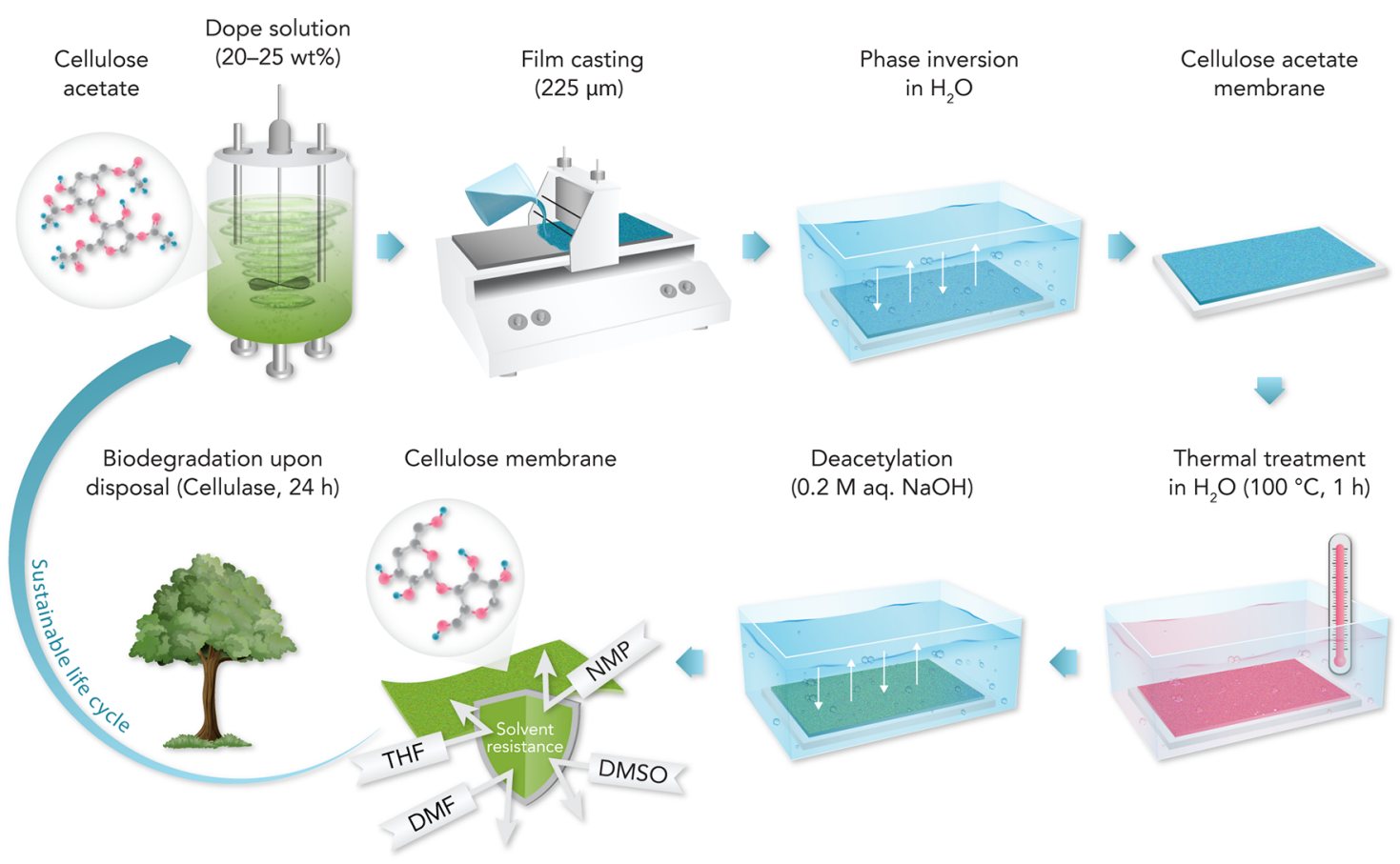

Figure 1. Proposed sustainable life cycle of biopolymeric membranes: the fabrication of cellulose membranes from the derivatized cellulose polymer with a sacrificial moiety (e.g., cellulose acetate with a sacrificial acetate moiety).

mers. $^{15}$ Therefore, greener fabrication of membranes has currently been set as a strategic goal, and considerable efforts have been made to improve the sustainability of membrane fabrication apart from improving the membrane performance. $^{15-18}$

Among the biobased polymers, cellulose is an important class of renewable biopolymer that is almost inexhaustible in nature, with an annual productivity of 100 billion tons. ${ }^{19}$ It is a polysaccharide composed of repeating D-glucose monomers, each with three hydroxyl groups. Such a structure of cellulose makes chemical modification very appealing, but its strong intermolecular $\mathrm{H}$-bonds render this semicrystalline polymer insoluble in most organic solvents. ${ }^{20,21}$ This feature makes cellulose membrane fabrication challenging with conventional methods such as phase inversion.

Only a handful of solvent mixtures can break apart the cellulose crystals to process it, such as aqueous transition metal complexes, $\mathrm{N}$-methylmorpholine $\mathrm{N}$-oxide (NMMO), and ionic liquids. Early studies on cellulose focused on the Lyocell process that utilizes NMMO monohydrate to process cellulose. $^{22-24}$ Notably, Volkov et al. ${ }^{25-27}$ have published a series of articles on the preparation of cellulose membranes using NMMO.

During membrane fabrication using the phase inversion technique, the polymer-solvent interaction is critical to effectively control the membrane morphology and performance. In addition, the processing solvent has a significant effect on the mechanical properties and crystal structure state of the resulting membranes. Hence, choosing the right solvent is very important, and limited solvent selection severely restricts the versatility of the membrane fabrication window, resulting in poor membrane performance.

It is important to note the need to use green solvents during membrane fabrication. Currently, most of the commercial membranes are fabricated with toxic solvents such as $N, N$ dimethylformamide (DMF), N,N-dimethylacetamide (DMAc), and $N$-methylpyrrolidone (NMP). ${ }^{28}$ To improve the sustainability of membrane fabrication, such toxic solvents must be replaced with greener alternatives. ${ }^{17,29}$ A number of promising alternatives have been reported recently, including PolarClean, ${ }^{30-32}$ Cyrene, ${ }^{33,34}$ methyl lactate, ${ }^{28,35}$ and triethyl phosphate. ${ }^{36}$ However, these solvents cannot be applied to cellulose membrane fabrication due to the solubility restriction.

Ionic liquids are another interesting class of solvents with decent solubility toward cellulose. Many studies on the application of ionic liquids to fabricate cellulose membranes have been published. ${ }^{20,37-39}$ Notably, Nunes et al. ${ }^{20}$ reported the fabrication of cellulose hollow fiber membranes with sufficient mechanical strength. However, the high cost of ionic liquids and their potential environmental impact make the industrial implementation of these solvents not yet practical. $^{40,41}$

To bypass the solubility limitation of cellulose, Peinemann et al. $^{42}$ reported on a novel regeneration technique to fabricate cellulose membranes from the trimethylsilyl cellulose (TSMC) polymer with a sacrificial trimethylsilyl functional group. The TSMC polymer exhibited high solubility in $n$-hexane, and the authors spin-coated a $10 \mathrm{~nm}$-thin dense film on the top of the polacrylonitrile membrane substrate. The sacrificial trimethylsilyl group was hydrolyzed in an aqueous $\mathrm{HCl}$ solution, and the resulting cellulose membrane showed outstanding mechanical rigidity and selectivity. Apart from TSMC, cellulose can be derivatized into many different forms, including cellulose acetate (CA), to modify its properties, such as solubility in solvents. $^{43}$

In this work, extending the regeneration strategy, we propose a simple yet elegant approach to fabricate cellulose membranes from CA with a sacrificial acetate functional group. In comparison to cellulose, the CA polymer is soluble in a wide range of solvents, enabling the utilization of various green solvents. In fact, $\mathrm{CA}$ is one of the earliest polymers used in membrane applications that have demonstrated competitive 
Table 1. Summary of the Prepared Membranes

\begin{tabular}{|c|c|c|c|}
\hline CODE & Polymer wt\% & Solvent wt\% & Note \\
\hline CA & \multirow{4}{*}{$25 \%$} & \multirow{4}{*}{$\begin{array}{l}37.5 \% \text { DMSO } \\
37.5 \% \text { acetone }\end{array}$} & Cast in $30^{\circ} \mathrm{C}$ waterbath \\
\hline CA-T & & & $\begin{array}{c}\text { Thermally Treated at } 100^{\circ} \mathrm{C} \\
\text { waterbath }\end{array}$ \\
\hline $\begin{array}{l}\text { CA-T-D } \\
\text { (CL) }\end{array}$ & & & $\begin{array}{c}\text { Deacetylated in } 0.2 \mathrm{M} \mathrm{NaOH} \\
\text { (Cellulose form) }\end{array}$ \\
\hline CA-D & & & $\begin{array}{l}\text { Deacetylated without Thermal } \\
\text { Treatment (Cellulose form) }\end{array}$ \\
\hline CA(DMSO) & $15 \%$ & $\begin{array}{l}42.5 \% \text { DMSO } \\
42.5 \% \text { acetone }\end{array}$ & \\
\hline $\mathrm{CA}(\mathrm{PC})$ & $15 \%$ & 85\% PolarClean & \\
\hline CA(ML) & $15 \%$ & 85\% Methyl Lactate & \\
\hline CA(TEP) & $15 \%$ & $85 \%$ TEP & \\
\hline
\end{tabular}

performance. Furthermore, CA can be easily deacetylated in a dilute alkaline solution to yield solvent-stable cellulose membranes. The concept of CA deacetylation has been reported to fabricate fibrous membranes; ${ }^{44,45}$ however, it has not yet been applied to expand the solvent selection to incorporate green solvents and to control the polymer-solvent interactions.

The proposed regeneration strategy is graphically illustrated in Figure 1 with a sustainable life cycle loop. The cellulose membranes fabricated in this study exhibited outstanding solvent resistance, rendering them as a potential candidate for organic solvent nanofiltration (OSN) technology. OSN is a new branch of the liquid-separation membrane process capable of separating molecules in harsh organic solvents with nanoprecision. The potential applications of OSN technology are promising, including solvent fractionation, solvent recovery without phase change, homogeneous catalyst recovery, and membrane reactors. ${ }^{46}$

The fabricated cellulose membranes exhibited a unique solvent transport behavior, and the detailed transport mechanism in solvent environments was investigated in detail to better understand the membrane-solvent interactions. Furthermore, the biodegradability of cellulose membranes was compared with that of conventional membranes, and qualitative life cycle evaluations of these two types of membranes were conducted. The proposed strategy to fabricate the cellulose membranes is simple, versatile, and sustainable, and we believe that this work will provide an insight into applying the current membrane fabrication knowledge to biodegradable polymers.

\section{EXPERIMENTAL SECTION}

Materials. Cellulose acetate $\left(50000 \mathrm{~g} \mathrm{~mol}^{-1}\right)$, dimethyl sulfoxide (DMSO), and acetone were purchased from Sigma-Aldrich and were used as the polymer, solvent, and cosolvent, respectively, as components for a dope solution. The nonwoven substrate (Novatex 2471) was acquired from Freudenberg Filtration Technologies (Germany). Sodium hydroxide $(\mathrm{NaOH})$, poly(propylene glycol) (PPG), and dyes (Table 1) were all purchased from Sigma-Aldrich. $N$-Methyl-2-pyrrolidone (NMP), N,N-dimethylformamide (DMF), methyl alcohol $(\mathrm{MeOH})$, ethyl alcohol $(\mathrm{EtOH})$, isopropyl alcohol (IPA), N,N-dimethylacetamide (DMAc), triethyl phosphate (TEP), methyl lactate, acetonitrile, hexane, and toluene were acquired from Sejin Chem (South Korea). PolarClean was purchased from Solvay Korea.
Membrane Fabrication. The cellulose acetate polymer was dried at $80{ }^{\circ} \mathrm{C}$ before use. A calculated amount of CA polymer at a certain weight percent was dissolved in a mixture of green solvents. Four different sets of green solvents were employed to prepare dope solutions as summarized in Table 1 (refer to Figure $S 1$ in the Supporting Information). The dope solution was stirred at room temperature until a homogeneous solution was obtained. The dope solution was then degassed before casting onto the polypropylene (PP) nonwoven substrate using a casting knife (YBA, Yoshimitsu, Japan) at room temperature. The knife thickness was adjusted to 225 $\mu \mathrm{m}$, and the casting speed was set at $25 \mathrm{~mm} \mathrm{~s}^{-1}$. This step was followed by immersing the cast solution in a coagulation bath containing water at $30^{\circ} \mathrm{C}$ for $10 \mathrm{~min}$ for phase inversion. Finally, the fabricated cellulose acetate membrane was stored in IPA until further use.

The prepared cellulose acetate membrane was then thermally treated. The membrane was first immersed in a water bath boiler at room temperature, and both water and the membrane were concurrently heated. Once the bath temperature attained $100{ }^{\circ} \mathrm{C}$, the membrane was further treated for $1 \mathrm{~h}$.

The thermally treated cellulose acetate membrane was then deacetylated to convert into cellulose using $\mathrm{NaOH}$ aqueous solution (refer to Figure S5 in the Supporting Information). Following deacetylation, the membrane was washed thoroughly with DI water to remove residual $\mathrm{NaOH}$. The fabricated cellulose membrane was kept in IPA until use.

Membrane Characterization, Biodegradability, and Performance Evaluation. The solvent stability of $\mathrm{CA}$ and cellulose samples was immersed in DMF, tetrahydrofuran (THF), NMP, and DMSO solvents for $24 \mathrm{~h}$ under ambient conditions. The mass of the samples was recorded and compared before and after immersion.

The surface and morphologies of CA and cellulose membranes were visualized using field emission scanning electron microscopy (FE-SEM, JSM-7800F, Japan) and atomic force microscopy (AFM, MultiMode-8-AM, Bruker). The hydrophilicity of membranes was investigated using the contact angle measurement (Biolin Scientific Attension Theta T200, Sweden) at ambient temperature. Chemical functional groups of the membranes were determined using attenuated total reflectance Fourier-transform infrared spectroscopy (ATR-FTIR, tracer-100, Shimadzu, Kyoto, Japan) in the range of $500-4000 \mathrm{~cm}^{-1}$. The crystalline phases of the membranes were examined with high-resolution X-ray diffraction (XRD, SmartLab, Rigaku corporation).

Thermal properties were analyzed by differential scanning calorimetry (DSC, Q100 V8.2 Build 268) using aluminum pans at a heating rate of $10{ }^{\circ} \mathrm{C} \mathrm{min}^{-1}$ under a nitrogen flow and by thermogravimetric analysis (TGA Q500 V6.2 Build 187) under a nitrogen atmosphere with a heating rate of $20{ }^{\circ} \mathrm{C} \mathrm{min}$. 
The biodegradation experiment was conducted with five different membranes-cellulose, CA, polysulfone (PS), polyimide (PI), and poly(benzimidazole) (PBI). All membranes were immersed in a cellulase solution (citrate buffer, $\mathrm{pH}$ of 6). The cellulase to polymer mass ratio in solution was 1:4. A control experiment was performed with a cellulose membrane immersed in deionized water. All solutions were loaded onto a shaker $(120 \mathrm{rpm})$ at $50{ }^{\circ} \mathrm{C}$ for $24 \mathrm{~h}$. The changes in morphology and mass were recorded.

The membrane performance was tested using either a dead-end cell apparatus or cross-flow system. Each experiment was conducted at least twice with an effective membrane surface area of $15.2 \mathrm{~cm}^{2}$. The solutes used for the experiment are summarized in Table 2. Feed

Table 2. Solutes Used in the Nanofiltration Performance Evaluation

\begin{tabular}{|ll}
\multicolumn{1}{c}{ solute $^{a}$} & MW $\left(\mathrm{g} \mathrm{mol}^{-1}\right)$ \\
\hline poly(propylene glycol) (0) & $400-1000$ \\
rose bengal (-) & 1017 \\
brilliant blue (-) & 825 \\
bromothymol blue (0) & 624 \\
hexaphenylbenzene (HPB) (0) & 535 \\
Janus green B (+) & 511 \\
crystal violet (+) & 407 \\
chrysoidine G (0) & 248
\end{tabular}

${ }^{a}(0)$ : neutral species, $(-)$ : negatively charged species, $(+)$ : positively charged species.

solutions containing $10 \mathrm{ppm}$ dyes or $2 \mathrm{~g} \mathrm{~L}^{-1}$ PPG (400-1000 g $\mathrm{mol}^{-1}$ ) were prepared. The dead-end filtration cell was filled with 200 $\mathrm{mL}$ of feed solution and stirred at $50 \mathrm{rpm}$ to prevent concentration polarization. The system was pressurized with nitrogen up to 20 bar.

For the cross-flow system experiments, the system was operated with an applied pressure of up to 30 bar with a tangential flow rate of $200 \mathrm{~L} \mathrm{~h}^{-1}$. The solution temperature was maintained at $30{ }^{\circ} \mathrm{C}$. Permeate samples for flux measurements were collected at $1 \mathrm{~h}$ interval, and samples to analyze membrane selectivity (e.g., rejection) were taken at the steady state flux.

The membrane solvent permeance $(B)\left(\mathrm{L} \mathrm{m}^{-2} \mathrm{~h}^{-1} \mathrm{bar}^{-1}\right)$ was determined by measuring the volumetric flow rate of permeate $(\Delta V)$
$\Delta t)$ per unit area $(A)$ per unit pressure $(\Delta P)$ according to the following equation

$$
B=\frac{\Delta V}{A \cdot \Delta t \cdot \Delta P}
$$

Rejection $\left(R_{\mathrm{i}}\right)$ of oligomers was evaluated with the following equation

$$
R_{\mathrm{i}}=\left(1-\frac{C_{\mathrm{P}, \mathrm{i}}}{C_{\mathrm{F}, \mathrm{i}}}\right) \times 100 \%
$$

where $C_{\mathrm{P}, \mathrm{i}}$ and $C_{\mathrm{F}, \mathrm{i}}$ are oligomer concentrations in permeate and in retentate solutions, respectively.

The permeate and retentate solute concentrations were determined using a high-pressure liquid chromatography (HPLC, YL910, Youngin Chromass) system equipped with a ultraviolet-visible (UV-vis) and evaporative light scattering detector (ELSD). The stationary phase was a RP C18 column, and the mobile phase was a gradient of DI water and acetonitrile $(\mathrm{MeCN})$ with a flow rate of 1 $\mathrm{mL} \min ^{-1}$. The ELSD chamber and drift tube temperatures were fixed at 28 and $55{ }^{\circ} \mathrm{C}$, respectively. The collected samples were solventswapped to $\mathrm{EtOH}$ prior to analysis.

\section{RESULTS AND DISCUSSION}

Membrane Design and Engineering. As the cellulose biopolymer is insoluble in most organic solvents, it is a sustainable alternative to conventional organic solvent nanofiltration (OSN) membranes. However, because of its insolubility, it is difficult to process into membranes in a sustainable route. In this study, cellulose acetate (CA) membranes with a sacrificial acetate moiety were first fabricated with a nonsolvent-induced phase separation (NIPS) technique using green solvents. To illustrate the versatility of this method, several green solvents such as PolarClean, triethyl phosphate (TEP), methyl lactate, and a mixture of DMSO-acetone were employed to fabricate CA precursor membranes. All of these solvents are considered greener compared to conventional solvents such as NMP, DMF, and DMAc. ${ }^{29,47}$ (please refer to Figure S1 in the Supporting Information for experimental details).
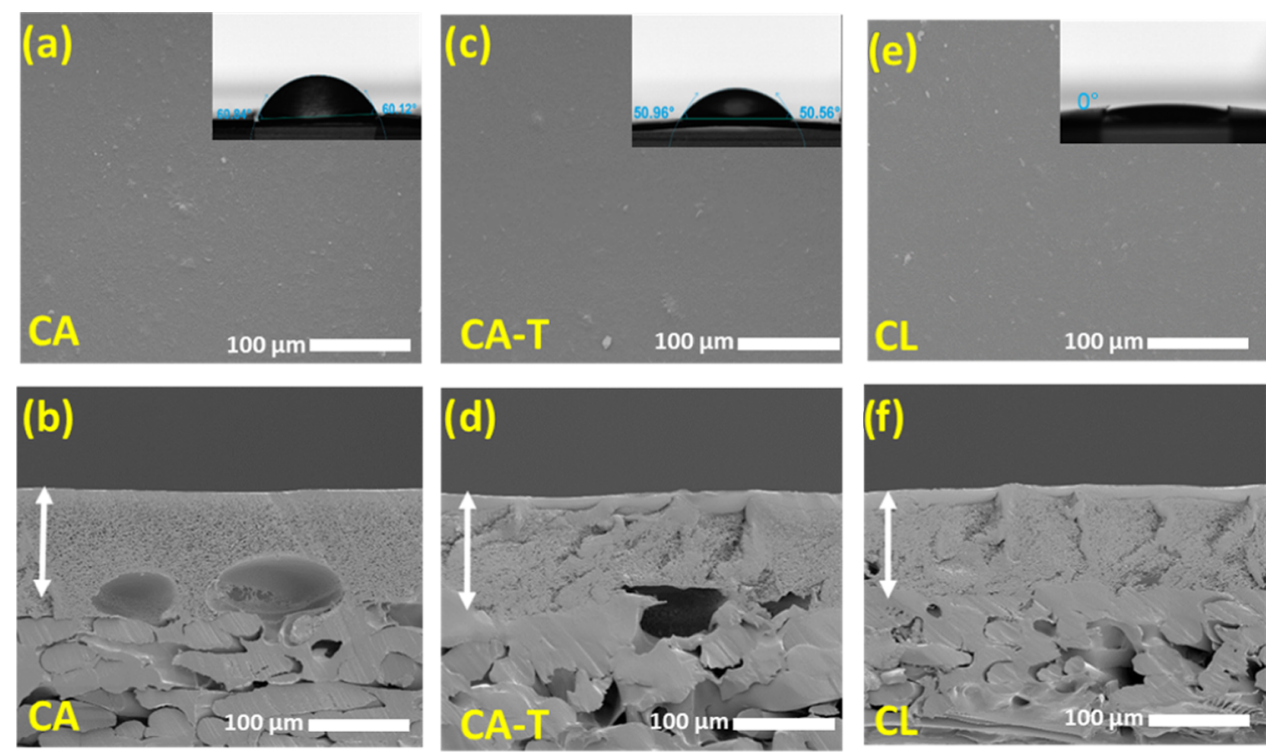

Figure 2. Surface and cross-sectional SEM images of (a, b) cellulose acetate (CA); (c, d) cellulose acetate after thermal treatment (CA-T); and (e, f) cellulose membrane after deacetylation $(\mathrm{CL})$. The actual membrane photographs and the water contact angle images are superimposed on the surface images. 
(a)

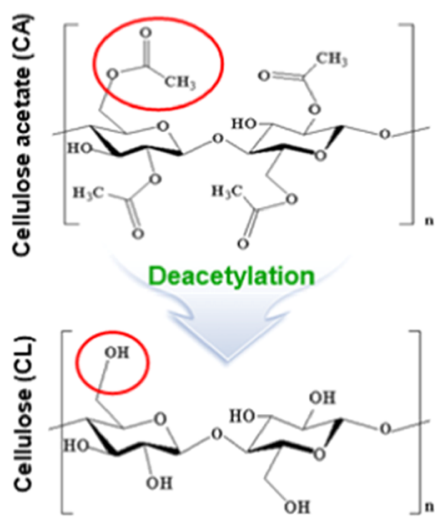

(d)

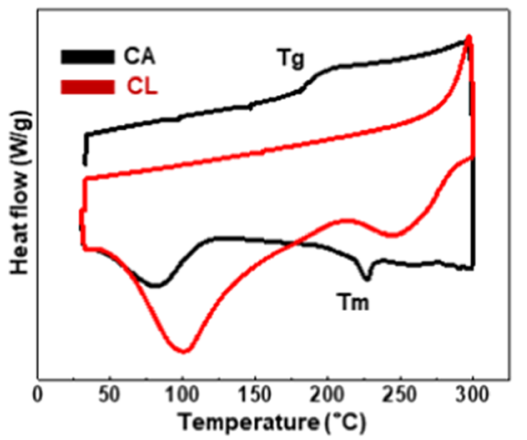

(b)

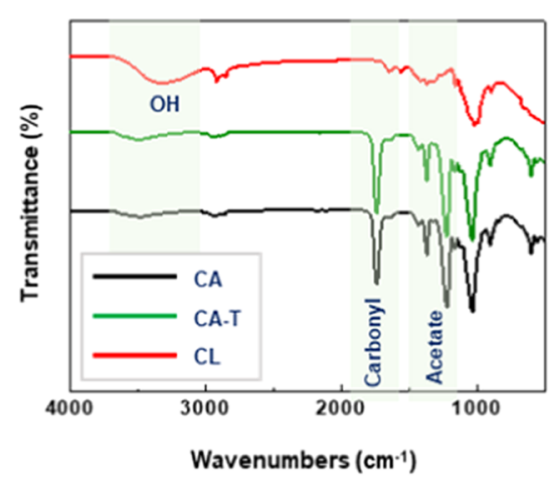

(c)

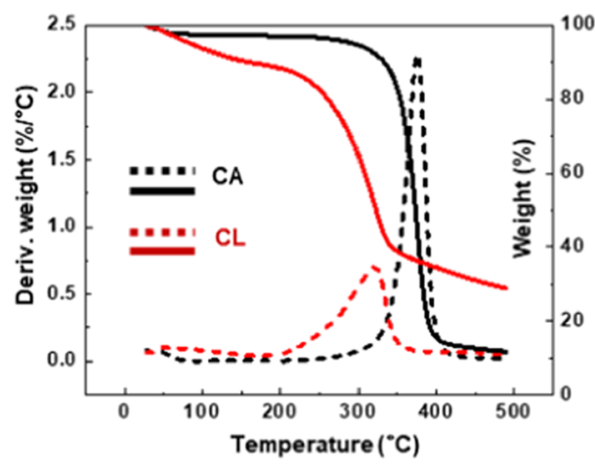

(e)

\section{Cellulose acetate (CA)}

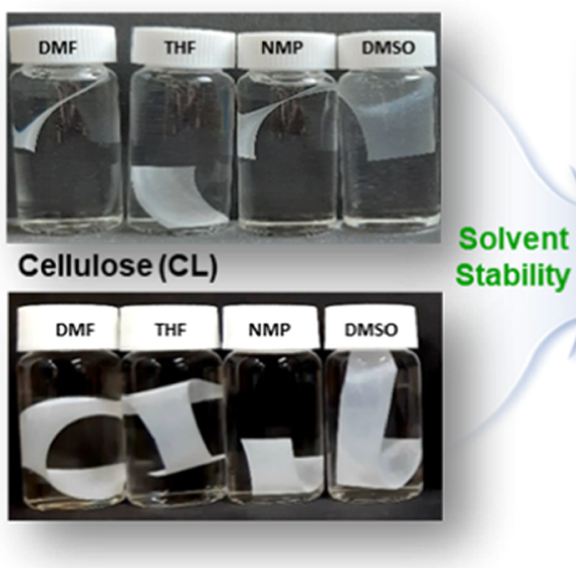

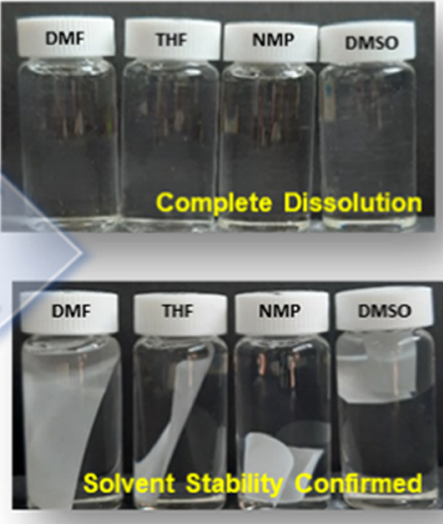

Figure 3. (a) Chemical structures of CA and cellulose before and after deacetylation; (b) FTIR spectra of CA, CA-T, and cellulose (CL) membranes; (c) thermogravimetric analysis (TGA); (d) differential scanning calorimetry (DSC) data; and (e) solvent stability test results of CA and cellulose membranes.

The fabricated CA membranes were initially thermally treated in a water bath to fine-tune the pore size, then subsequently deacetylated in an aqueous $\mathrm{NaOH}$ solution to remove the sacrificial acetate group, and convert them to a solvent-stable cellulose membrane. The morphology of the membranes is shown in Figure 2. The prepared CA membranes exhibited a dense surface without any visible pores, and their cross-section also exhibited a compact structure without noticeable macrovoids. As OSN membranes require nanofiltration performance (pore size in the nanometer range), the fabrication parameters were tailored to induce dense structures (refer to Figures S2-S4 in the Supporting Information).

The prepared CA membranes were relatively hydrophilic with a water contact angle (WCA) of approximately $58^{\circ}$. The WCA maintained the same range after thermal treatment since the material chemistry had not been modified. Upon deacetylation to convert to the cellulose form, the membranes became superhydrophilic with a WCA of $0^{\circ}$. There was no observable change in the surface and cross-sectional morphology following deacetylation. Notably, both CA and cellulose (CL) membranes exhibited excellent mechanical flexibility, which is an important property for scaling up and manufacturing membrane modules.
The chemical structures of CA and cellulose, with the latter produced by deacetylating of the former, are shown in Figure $3 \mathrm{a}$, and the chemical transformation from CA to cellulose was verified by FTIR, as shown in Figure 3b. CA membranes can be characterized by two intensive peaks at $1720 \mathrm{~cm}^{-1}$ from the acetyl group and $1230 \mathrm{~cm}^{-1}$ from the acetate group. ${ }^{48-51}$ These characteristic peaks completely disappeared in the cellulose spectrum. Furthermore, the broad peak at 3000$3600 \mathrm{~cm}^{-1}$ representing a characteristic vibrational mode of the $\mathrm{OH}$ bond also appeared after deacetylation. It was possible to fine-tune the degree of deacetylation by controlling the deacetylation conditions (refer to Figure S5 in the Supporting Information). In this work, complete deacetylation was reproducibly achieved in $0.2 \mathrm{M} \mathrm{NaOH}$ without discernable degradation of the membrane.

The thermal properties analyzed by TGA (Figure 3c) and DSC (Figure 3d) also corroborate the FTIR analysis, showing a clear distinction between CA and cellulose. The TGA data showed that the $\mathrm{CA}$ membranes began to decompose at temperatures above $300{ }^{\circ} \mathrm{C}$, while the weight loss of the cellulose membrane occurred at around $200{ }^{\circ} \mathrm{C}$ after the initial loss of moisture at $100-120{ }^{\circ} \mathrm{C} .{ }^{52,53}$ It is worth pointing out that cellulose membranes exhibited lower thermal stability than that of CA membranes. It has been reported that above 200 ${ }^{\circ} \mathrm{C}$, the cellulose polymer chains isomerize into volatile 
a)

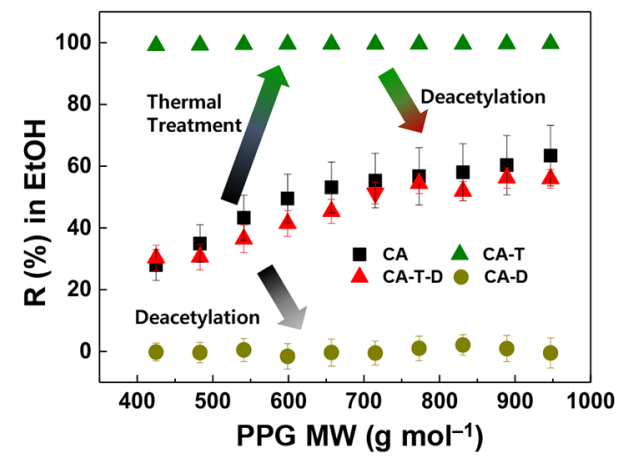

c)

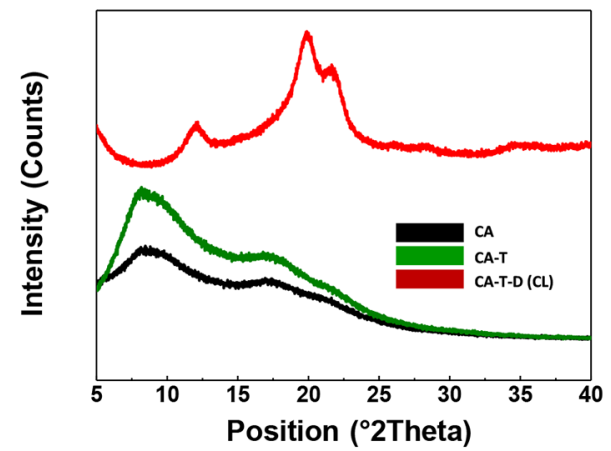

b)

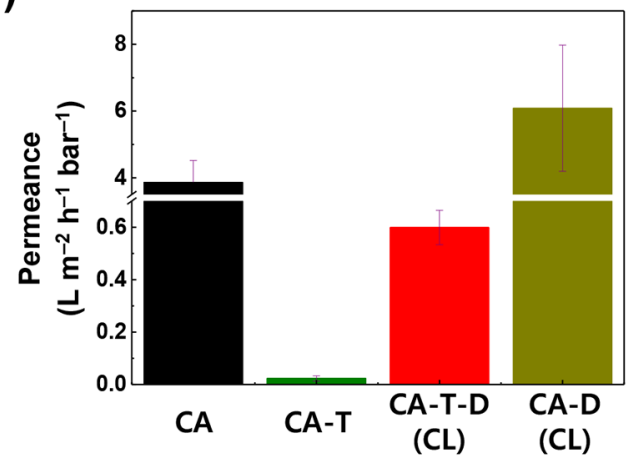

d)

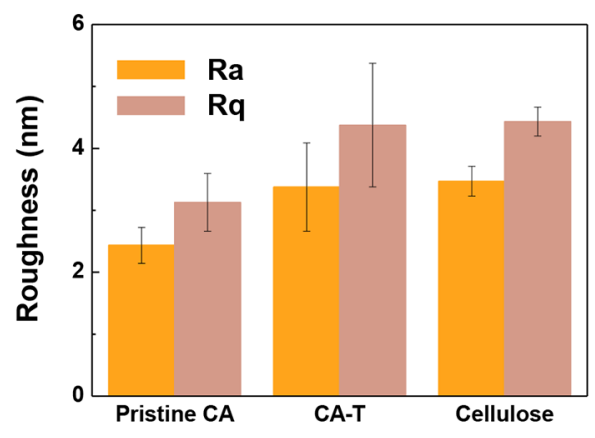

e)

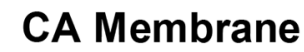

CA-T Membrane

CL Membrane

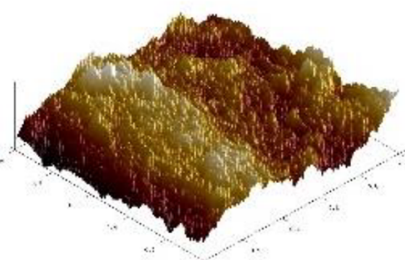

f)
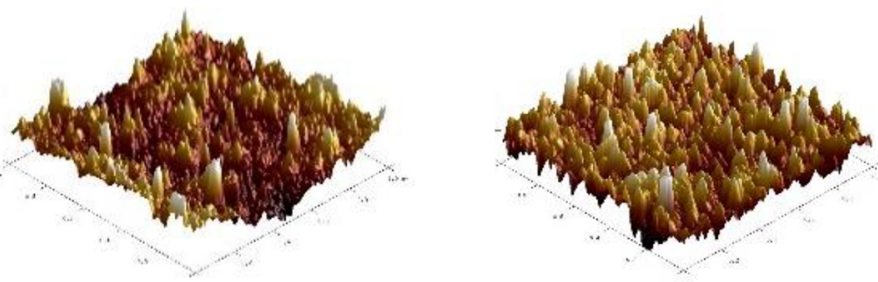

CA Membrane

CA-T Membrane

CL Membrane
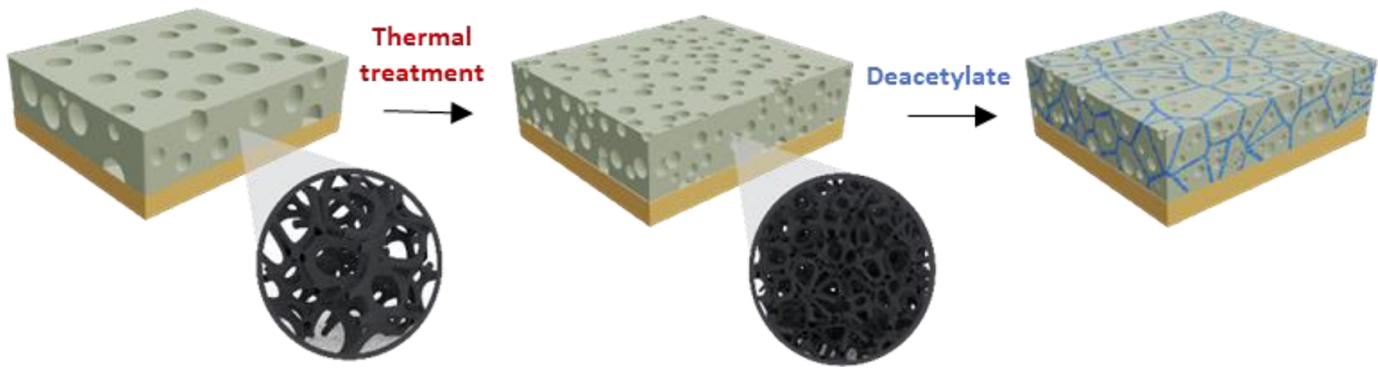

Figure 4. (a) Effect of thermal treatment and deacetylation step on the membrane separation performance, analyzed using PPG solutes in EtOH. Membranes were fabricated using $25 \%$ polymer dope solution; (b) corresponding solvent permeance data in EtOH; (c) XRD data showing the crystalline state of the membrane; (d, e) AFM data with roughness values and surface morphology; and (f) graphical illustration of the changes in the membrane pore structures.

levoglucosan, ${ }^{54,55}$ which then decomposes to release water as a byproduct.

DSC results of the CA membranes revealed a distinct melting peak at $275^{\circ} \mathrm{C}$ and a glass transition peak at $195{ }^{\circ} \mathrm{C}$. In the case of cellulose, the range of the initial solvent evaporation peak $\left(35-150{ }^{\circ} \mathrm{C}\right)$ was wider and larger compared with that of CA. ${ }^{53,56-58}$ This broad peak can be attributed to the captured water molecules in the crystalline region, which form strong hydrogen bonds with cellulose polymer chains.
The second broad peak above $200{ }^{\circ} \mathrm{C}$ in the cellulose spectrum originated from the evaporation of levoglucosan and byproduct water from cellulose isomerization. ${ }^{55}$ It can be clearly distinguished from the CA melting peak $\left(T_{\mathrm{m}}\right)$ as neither $T_{\mathrm{c}}$ nor $T_{\mathrm{g}}$ could be observed in the cooling cycle data of the cellulose spectrum.

The solvent stability data of the fabricated CA and cellulose membranes are summarized in Figure 3e. All CA membranes dissolved away in common organic solvents as expected. Upon 
(a)

(d)
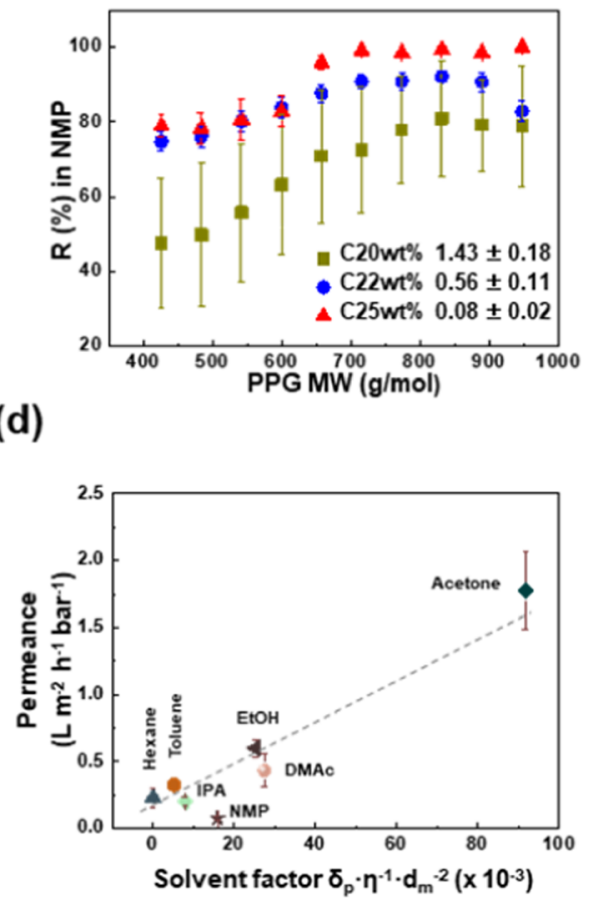

(b)

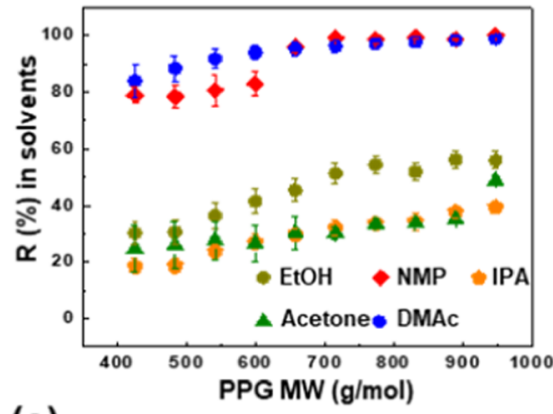

(e)

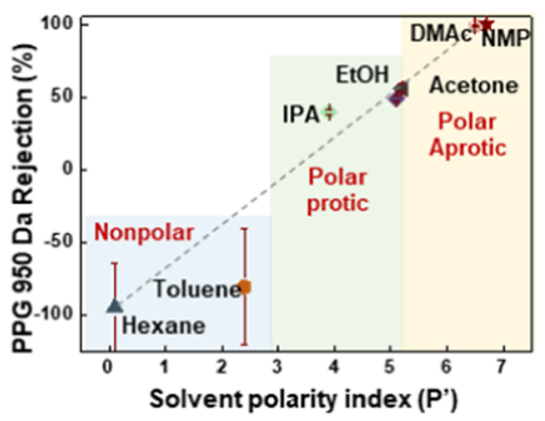

(c)

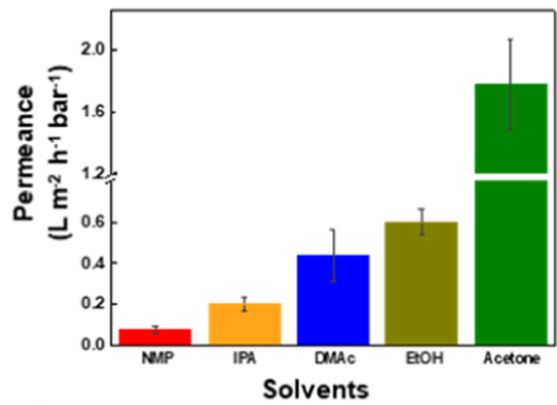

(f)

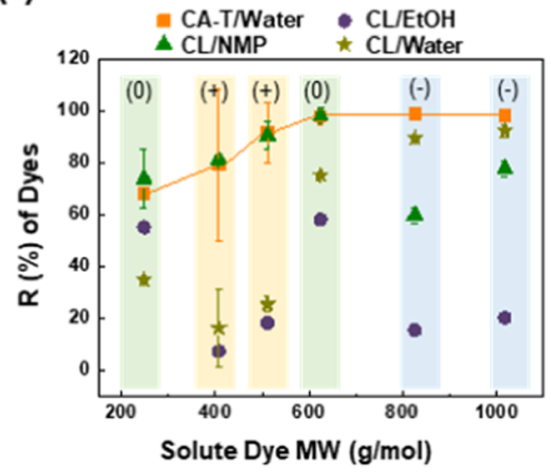

Figure 5. CA and cellulose membrane separation performance using various solutes and solvents: (a) cellulose membrane PPG rejection in NMP at different polymer dope compositions; (b) 25 wt \% cellulose membrane PPG rejection in polar solvents; (c) 25 wt \% cellulose membrane permeance in polar solvents; (d) cellulose membrane permeance plotted as a function of the solvent factor parameter; (e) cellulose membrane rejection of $950 \mathrm{~g} \mathrm{~mol}^{-1} \mathrm{PPG}$ solute versus solvent polarity index; and (f) comparison of charged and neutral solute rejection trends of CA and cellulose membranes in polar solvents.

deacetylation, the resulting cellulose membranes were completely solvent-resistant, with undetectable mass loss (refer to Figure S6 in the Supporting Information).

This set of data clearly demonstrates that solvent-resistant OSN cellulose membranes can be fabricated sustainably from CA with a sacrificial acetate moiety, with green solvents, and a simple deacetylation step in the aqueous media. Particularly, using the proposed method to fabricate solvent-stable membranes is more sustainable than conventional OSN membranes. For instance, most polymer membranes only become solvent-stable following chemical cross-linking in bifunctional amines in methanol solution ${ }^{59,60}$ or benzyl halides in acetonitrile solution ${ }^{61}$ that are unsustainable.

Separation Performance. The nanofiltration performance of the membranes was tested using the common PPG marker, as shown in Figure 4a,b. In comparison to the pristine CA membranes (CA), the thermally treated CA membranes (CA$\mathrm{T}$ ) exhibited quantitative solute rejection up to $100 \%$ for all PPG solutes in the range of 400-1000 $\mathrm{g} \mathrm{mol}^{-1}$, indicating narrowing of the pores. The CA polymer is thermally plasticizeable, and thermal treatment can contract the membrane pore size. ${ }^{62}$

In comparison, upon deacetylation of the thermally treated CA membranes (CA-T-D), i.e., cellulose (CL) membrane, the rejection considerably decreased, which indicates an increase in the pore size. The CA membranes deacetylated without thermal treatment (CA-D), which was done as a control experiment, exhibited even lower rejection, showing no nanofiltration properties. Hence, the thermal treatment step prior to deacetylation is necessary to obtain membranes with molecular sieving properties in the nanofiltration range (solute molecular weight (MW) between 200-1000 $\mathrm{g} \mathrm{mol}^{-1}$ ).

The decrease in PPG rejection upon deacetylation can be attributed to the combination of two simultaneous effects. First, the scission of bulky acetyl groups from the polymer framework could widen the membrane pores. However, it is uncertain whether the void will remain as pores or it will close due to the strong $\mathrm{H}$-bonding between the cellulose monomeric units. Note that the solvent resistance of cellulose membranes arises from the inter- and intramolecular H-bonding network.

Second, the deacetylated cellulose membrane exhibited intense crystalline peaks at $2 \theta$ values of 19.8 and $21.6^{\circ}$, corresponding to (110) and (020) crystal planes, respectively (Figure $4 c$ ). These peaks indicate the presence of type-2 cellulose crystals ${ }^{63}$ composed of antiparallel sheets with strong interlayer hydrogen bonding. In comparison, both CA and CA$\mathrm{T}$ showed broad amorphous peaks. Hence, it can be deduced that grain boundaries between cellulose crystals act as large pathways for PPG solutes to permeate. The formation of grain boundaries also enhanced the membrane permeance, indicating high connectivity between grain boundaries. The surface roughness increased after the thermal treatment and also upon deacetylation (Figure 4e). The results suggest that controlling the cellulose crystal size (and the corresponding grain boundaries) is key for fine-tuning the cellulose membrane performance and that it can be achieved by controlling the parameters from the phase inversion step.

Based on these results, possible pore structures of the membranes are illustrated in Figure 4f. The proposed pore morphology may not be accurate, as the pore size alone cannot describe the permeance and selectivity of the nanofiltration 
membrane, and other factors such as solvent-membrane interaction and solute polarity must be considered simultaneously.

The performances of CA and cellulose membranes, prepared at different dope solution concentrations, have been tested using various solutes and solvents (Figure 5). Expectedly, the higher polymer concentration in the dope solution progressively led to higher rejection, indicating smaller pores (Figure 5a). The PPG solute rejections of the 25 wt \% cellulose membrane were determined using a series of polar solvents (Figure $5 \mathrm{~b}$ ) with the respective permeance (Figure 5c). The PPG rejection data in nonpolar solvents (toluene and hexane) are summarized in Figure S9 in the Supporting Information. Note that solvent permeation and solute rejection mechanisms are highly complex systems, and many factors must be considered simultaneously to accurately explain the observed trends.

A closer look at the data shows that PPG rejection values are high in NMP and DMAc, moderate in EtOH, IPA, and acetone, and even negative in toluene and hexane (Figure S9 in the Supporting Information). To extract meaningful trends from the data, the permeance and rejection data were plotted against well-known physical parameters-permeance versus solvent factor (Figure $5 \mathrm{~d}$ ) and rejection versus polarity index (Figure 5e).

The solvent factor is a phenomenological parameter first proposed by Livingston et al. ${ }^{64}$ to describe the difference in permeance between solvents.

$$
\text { solvent factor }(\psi)=\frac{\delta_{\mathrm{p}}}{\eta \cdot d_{\mathrm{m}}^{2}}
$$

where $\delta_{\mathrm{p}}, \eta$, and $d_{\mathrm{m}}$ refer to the polar solubility parameter, viscosity, and molar diameter of the solvent, respectively. Generally, viscosity is the dominant factor, but the polar solubility parameter of a solvent also plays a role. All of the reported OSN membranes show a positive correlation, and cellulose membranes fabricated in this work also exhibit the similar trend, indicating that the membrane has molecular sieving pores.

When the PPG solute rejection $\left(950 \mathrm{~g} \mathrm{~mol}^{-1}\right)$ was plotted against the solvent polarity index (Figure $5 \mathrm{e}$ ), a linear positive correlation was obtained. Based on the trend, the solvents can be roughly classified into three different groups: polar protic solvents (EtOH and IPA), polar aprotic solvents (NMP, DMAc, and acetone), and nonpolar solvents (toluene and hexane).

All polar solvents, both protic and aprotic, displayed positive rejection values. More specifically, polar protic solvents such as EtOH and IPA exhibited moderate PPG rejection values in the 20-50\% range. Since protic EtOH and IPA (also PPG) can form $\mathrm{H}$-bonds with the cellulose, PPG can permeate through the membrane via the hopping mechanism, ${ }^{65-67}$ lowering the observed rejection. On the other hand, PPG rejection in polar aprotic solvents (NMP and DMAc) was high, near 100\% across the upper MW ranges. As polar aprotic solvents are relatively viscous with weak $\mathrm{H}$-bond donating capabilities, their main permeation mechanism is via convection with low permeance. Simultaneously, PPG prefers to partition into NMP and DMAc over cellulose (refer to Table S2 in the Supporting Information), corroborating the high rejection trends.
One peculiar outlier to this trend was acetone, which is also classified as a polar aprotic solvent. The PPG rejection in acetone was in the $20-50 \%$ range. This can be explained by the fact that acetone has a very high solvent factor $(\psi)$, leading to much faster permeance compared to other aprotic solvents (Figure 5d). Generally, for convective transport through pores, high flux leads to lower rejection. Acetonitrile is another polar aprotic solvent with a very high solvent factor, which resulted in low PPG rejection (refer to Figure S7/Section 4 and Table S1/Section 7 in the Supporting Information).

An interesting observation from Figure $5 \mathrm{e}$ is the negative rejection of cellulose membranes in nonpolar solvents with a low polarity index. Such negative rejection data are seldom reported in the OSN literature, and it is usually observed for charged solutes. ${ }^{68,69}$ The concept of negative rejection becomes more intuitive if the solute flux and solvent flux are considered independently. More specifically, negative rejection is observed if the solute flux is faster than the solvent flux, i.e., permeate concentration is higher than the retentate concentration. In the case of the PPG (solute)-toluene (solvent)cellulose (membrane) ternary system, three different interactions must be considered simultaneously: solvent-membrane, solute-membrane, and solute-solvent interactions. Noting that cellulose is superhydrophilic (polar) and toluene is nonpolar, the solvent-membrane interaction is considerably weaker than the other two interactions, leading to the observed negative rejection trends.

The unique transport behavior of cellulose membranes was observed in polar solvents with other solutes such as neutral, positively, and negatively charged dyes (Figure $5 \mathrm{f}$ ). The CA precursor membranes were used as a control experiment. The rejection of CA membranes in ethanol displayed an ordinary increasing trend with solute size, regardless of the solute charge or shape. Such a trend indicates that there is a minimal solutemembrane interaction, and the separation mechanism is primarily via the size-exclusion mechanism.

In comparison, for cellulose membranes, the trend was drastically different. In ethanol, both positively and negatively charged solutes exhibited considerably lower rejection compared to that of neutral solutes, regardless of the solute size. In the case of NMP, only negatively charged solutes tend to display lower rejection. In water, on the other hand, only the positively charged solutes exhibited particularly low rejection. In all solvents, neutral solutes followed the intuitive size-based exclusion trend. Such data indicate that the charge interaction between the solute and membrane dominates over the simple size-exclusion mechanism for cellulose membranes. (Please find more detailed discussion about these trends in Section 9 in the Supporting Information.)

The observed transport behavior of cellulose membranes in organic solvents is strikingly different from that of other conventional OSN membranes. Particularly, the effects of $\mathrm{H}$ bonding, polarity, and charge (dipole) clearly outweigh the simple size-exclusion mechanism of the membranes. This unusual trend opens new avenues for further investigation to elucidate the underlying mechanisms and for developing new cellulose-based molecular sieving membranes in organic solvents. For instance, the observed dramatic difference in solute rejection as a function of the solvent property could be further exploited in perstraction ${ }^{70}$ and organophilic pervaporation $^{71,72}$ applications to augment energy-intensive distillation processes. 
(a)

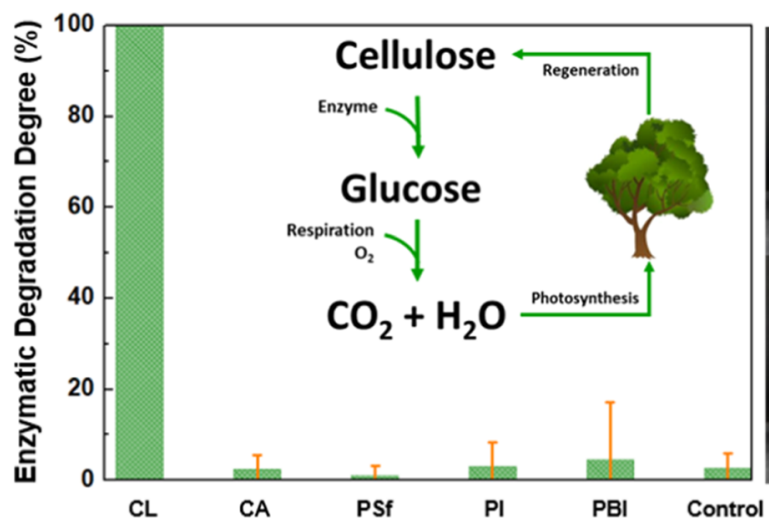

(b)

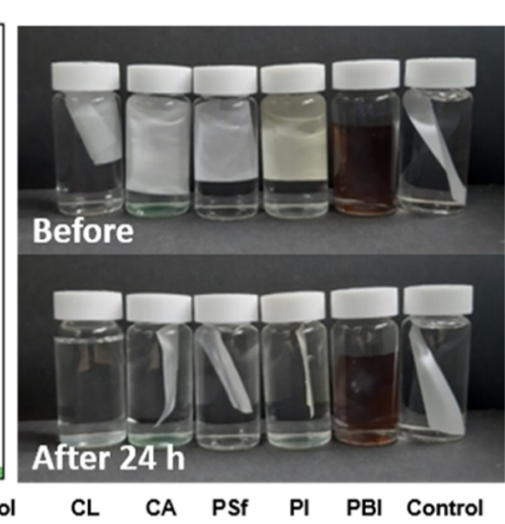

Figure 6. Biodegradation of the cellulose membrane and common polymer-based membranes: (a) mass loss after $24 \mathrm{~h}$ and (b) photographs of membrane samples before and after enzymatic degradation.

\section{Conventional OSN membrane life cycle}

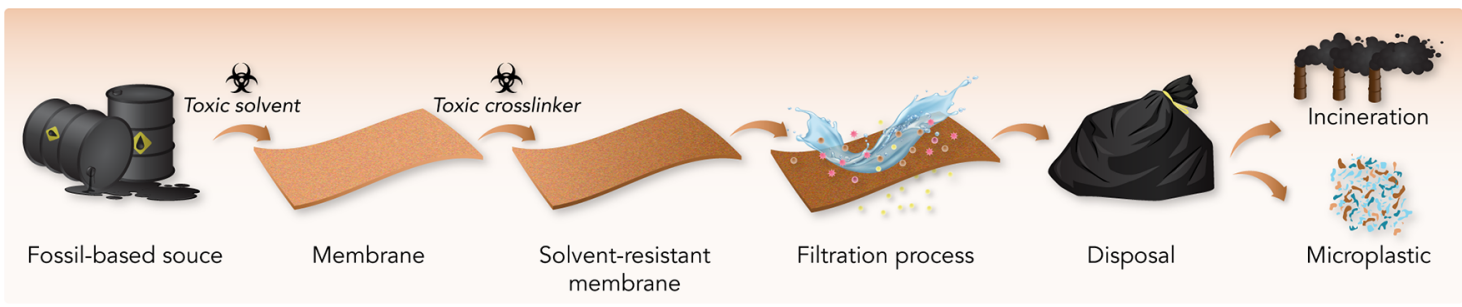

Sustainable OSN membrane life cycle

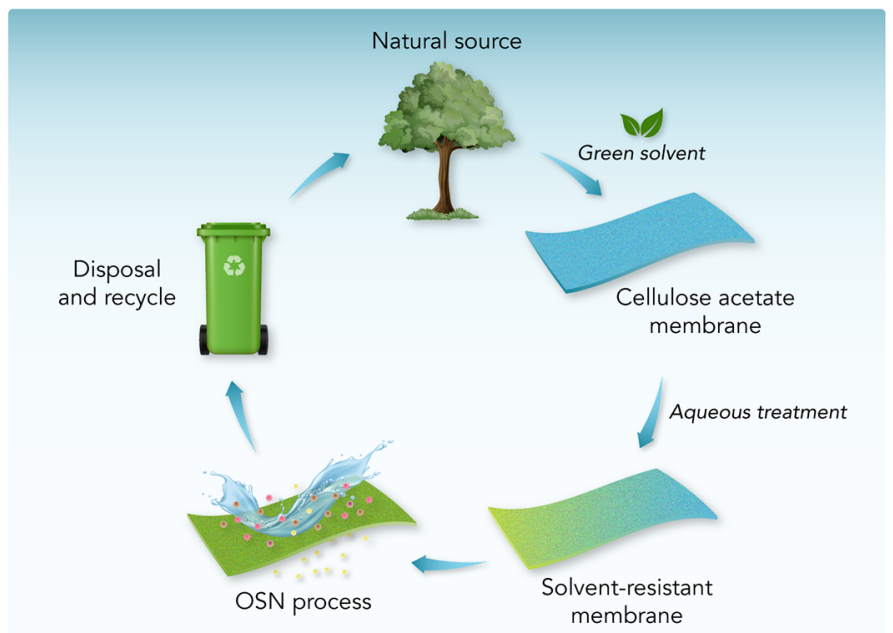

Figure 7. Qualitative life cycle assessment of conventional OSN membranes and the cellulose membranes fabricated in this work.

Life Cycle Assessment. Apart from the surprising transport behavior of cellulose membranes, cellulose membranes exhibit strong solvent resistance and hence can be a suitable and sustainable candidate for OSN membranes. In comparison to other conventional OSN membranes, cellulose membranes are bioderived with abundant natural sources. In addition, importantly, cellulose membranes are biodegradable. Under the regulations of the European standard EN 13432, ${ }^{19}$ biodegradability means that at least $90 \%$ of the constituents of an item can be converted into nontoxic end products (e.g., water, $\mathrm{CO}_{2}$, and biomass) under standard conditions.

In this work, the biodegradability of cellulose membranes was assessed in comparison to that of other conventional membrane materials such as CA, polysulfone (PS), polyimide
(PI), and polybenzimidazole (PBI). All membranes were immersed in an enzymatic cellulase solution, and a control experiment was performed with the cellulose membrane immersed in deionized water. The cellulose membranes showed $100 \%$ biodegradation, while other polymers did not show noticeable biodegradation under the same experimental conditions (Figure 6). The control experiment without the cellulase enzyme confirmed that the biodegradation mechanism was an enzymatic reaction that cleaved cellulose chains into oligosaccharides. There is a considerable diversity in cellulolytic microorganisms with different capacity to biodegrade cellulose, but nature has evolved to sustainably recycle cellulosic materials. ${ }^{73}$ 
Although the potential of cellulose membranes has already been reported in the literature, ${ }^{26,38,74-76}$ most studies resort to using ionic liquids or NMMO solvent to prepare a dope solution due to the poor solubility of cellulose in common solvents. In comparison, the proposed method to fabricate cellulose membranes from sacrificial CA membranes in the present study offers two distinct advantages. First, the CA polymer can be solubilized in a wide range of solvents, and novel green (also economical) solvents such as PolarClean, Cyrene, TEP, and methyl lactate could be employed. The polymer-solvent interaction is the most important factor to fine-tune the membrane morphology and pore size distribution. Hence, the proposed method can allow better control of such features and improve the membrane performance. Second, the CA polymer is thermally plasticizable, and thermal treatment can be applied to narrow the pore size distribution. Thermal treatment is particularly useful in fabricating membranes with molecular sieving nanofiltration properties, as it is more effective in the nanometer-range pores. ${ }^{62}$ These two advantages enable much more versatile control of the cellulose membrane morphology and performance than the conventional methods, and the proposed method will certainly make the production of cellulose membranes more economical and sustainable. It should be noted that direct fabrication of cellulose membranes from cellulose could offer a more sustainable route, and identifying suitable solvents that can solvate cellulose is also an important research topic that should be pursued.

Figure 7 summarizes the qualitative life cycle of conventional OSN membranes versus that of the cellulose membranes proposed in this work. The life cycle of conventional OSN membranes begins with the chemical synthesis of polymer resins from fossil fuels. These membranes are fabricated via the phase inversion method.

To impart solvent stability to the conventional membranes, the polymer chains must be chemically cross-linked using toxic bifunctional amines, epoxides, or benzylhalides. The crosslinking step proceeds in organic solvents such as methanol and acetonitrile, appending further solvent intensity. The lifetime of OSN membranes has not been fully investigated yet, but upon disposal, the cross-linked membranes are either incinerated or buried in a landfill. Incineration inevitably generates $\mathrm{CO}_{2}$ along with nitrous/sulfurous compounds, and landfill waste is not biodegraded but decays into microplastics, generating more environmental issues.

On the other hand, the cellulose polymer is abundantly available in nature. Cellulose can be converted to the acetate form during extraction from its sources. ${ }^{50,57,77}$ CA precursor membranes can be fabricated using the phase inversion technique, as has been done in this work. To give solvent resistance to the CA membranes, cellulose can be regenerated via a simple alkali treatment in aqueous solution. The fabricated cellulose membranes can be used for, but not limited to, OSN applications. Upon disposal, they can be fully biodegraded in a carbon-neutral manner without any concerns of microplastics.

In the present work, the regeneration strategy was applied to the CA polymer with a sacrificial acetate moiety, but cellulose can be derivatized into many other forms (e.g., TSMC) $)^{42,78-81}$ all of which exhibit a unique behavior that can be utilized during membrane fabrication processes. In addition, it can be envisioned that the proposed method will be extended to many other biopolymers such as chitosan, alginate, and collagen.

\section{CONCLUSIONS}

In this work, solvent-resistant cellulose membranes were prepared from cellulose acetate with a sacrificial acetate moiety. The proposed method widens the scope of solvent selection for dope preparation, allowing versatile control of the cellulose membrane morphology and performance. Green solvents such as DMSO-acetone, PolarClean, methyl lactate, and TEP were used to fabricate CA membranes. A simple deacetylation step in aqueous $\mathrm{NaOH}$ solution fully removed the sacrificial acetate moiety from the CA membranes to form solvent-resistant cellulose membranes. The fabricated cellulose membranes exhibited excellent solvent resistance in organic solvents, rendering them as a sustainable alternative for OSN applications. Thermal treatment at the CA state was effective in fine-tuning the membrane pore size, whereas the deacetylation step induced the formation of crystalline grain boundaries that loosened the membrane selectivity. Cellulose membranes exhibited an unusual transport behavior in organic solvents. The solute rejection ranged from $100 \%$ in a polar NMP solvent down to $-100 \%$ in nonpolar toluene. Such wide difference in solute rejection could present an interesting separation opportunity not only in OSN but also in perstraction and organophilic pervaporation applications. Furthermore, the cellulose membranes exhibited excellent biodegradability compared to that of other fossil-based polymer membranes. The regeneration strategy investigated in this work can be applied to most of the modified cellulose derivatives to effectively control membrane performance. Hence, we envision that the proposed methodology will enable sustainable membrane fabrication not only in the OSN field but also in all areas of membrane technology to replace fossil-based polymers to become a truly sustainable separation platform.

\section{ASSOCIATED CONTENT}

\section{(s) Supporting Information}

The Supporting Information is available free of charge at https://pubs.acs.org/doi/10.1021/acssuschemeng.1c08554.

Membrane fabrication with green solvents; deacetylation condition optimization; mass change in stability experiment; membrane performance; cross-compared membrane performance; nonpolar solvent solute rejection; solvent properties and analysis of Hansen distance; octanol-water partition coefficient of PPG; and discussion on charge and different rejection of dyes (PDF)

\section{AUTHOR INFORMATION}

\section{Corresponding Authors}

Hoik Lee - Research Institute of Industrial Technology Convergence, Korea Institute of Industrial Technology, Ansansi 15588 Gyeonggi-do, Republic of Korea; Email: hoik@ kitech.re.kr

Gyorgy Szekely - Advanced Membranes and Porous Materials Center, Physical Science and Engineering Division (PSE), King Abdullah University of Science and Technology (KAUST), Thuwal 23955-6900, Saudi Arabia; (1) orcid.org/0000-0001-9658-2452;

Email: gyorgy.szekely@kaust.edu.sa

Jeong F. Kim - Department of Energy and Chemical Engineering, Incheon National University (INU), Incheon 22012, Republic of Korea; Innovation Center for Chemical 
Engineering, Incheon National University (INU), Incheon 22012, Republic of Korea; Email: jeongkim@inu.ac.kr

\section{Authors}

Hai Yen Nguyen Thi - Department of Energy and Chemical Engineering, Incheon National University (INU), Incheon 22012, Republic of Korea

Sumin Kim - Department of Energy and Chemical Engineering, Incheon National University (INU), Incheon 22012, Republic of Korea

Bao Tran Duy Nguyen - Department of Energy and Chemical Engineering, Incheon National University (INU), Incheon 22012, Republic of Korea

Daseul Lim - Department of Energy and Chemical Engineering, Incheon National University (INU), Incheon 22012, Republic of Korea

Sushil Kumar - Advanced Membranes and Porous Materials Center, Physical Science and Engineering Division (PSE), King Abdullah University of Science and Technology (KAUST), Thuwal 23955-6900, Saudi Arabia

Complete contact information is available at: https://pubs.acs.org/10.1021/acssuschemeng.1c08554

\section{Notes}

The authors declare no competing financial interest.

\section{ACKNOWLEDGMENTS}

This work was supported by the National Research Foundation of Korea (NRF) grant funded by the Korean government (MSIT) (Nos. 2020R1C1C100787612 and 2021M3H4A1A0409288511). The postdoctoral fellowship from the King Abdullah University of Science and Technology (KAUST) is gratefully acknowledged (S.K.). The research reported in this publication was supported by funding from KAUST.

\section{REFERENCES}

(1) Face Mask Market by Nature (Disposable, Reusable), Type (Surgical, Respirator, Others), End-Use (Hospitals \& Clinics, Industrial \& Institutional, Personal/Individual Protection), and Region - Global Forecast to 2025; Markets and Markets Research Private Ltd., 2020.

(2) Xu, E. G.; Ren, Z. J. Preventing masks from becoming the next plastic problem. Front. Environ. Sci. Eng. 2021, 15, No. 125.

(3) Miller, H. A.; Bouzek, K.; Hnat, J.; Loos, S.; Bernäcker, C. I.; Weißgärber, T.; Röntzsch, L.; Meier-Haack, J. Green hydrogen from anion exchange membrane water electrolysis: a review of recent developments in critical materials and operating conditions. Sustainable Energy Fuels 2020, 4, 2114-2133.

(4) Salvatore, D. A.; Gabardo, C. M.; Reyes, A.; O’Brien, C. P.; Holdcroft, S.; Pintauro, P.; Bahar, B.; Hickner, M.; Bae, C.; Sinton, D.; Sargent, E. H.; Berlinguette, C. P. Designing anion exchange membranes for CO2 electrolysers. Nat. Energy 2021, 6, 339-348.

(5) Alabi, A.; AlHajaj, A.; Cseri, L.; Szekely, G.; Budd, P.; Zou, L. Review of nanomaterials-assisted ion exchange membranes for electromembrane desalination. npj Clean Water 2018, 1, No. 10.

(6) Duy Nguyen, B. T.; Nguyen Thi, H. Y.; Nguyen Thi, B. P.; Kang, D.-K.; Kim, J. F. The Roles of Membrane Technology in Artificial Organs: Current Challenges and Perspectives. Membranes 2021, 11, No. 239.

(7) Wang, D.; Yuan, H.; Chen, Y.; Ni, Y.; Huang, L.; Mondal, A. K.; Lin, S.; Huang, F.; Zhang, H. A cellulose-based nanofiltration membrane with a stable three-layer structure for the treatment of drinking water. Cellulose 2020, 27, 8237-8253.
(8) Volkov, A. V.; Korneeva, G. A.; Tereshchenko, G. F. Organic solvent nanofiltration: prospects and application. Russ. Chem. Rev. 2008, 77, 983-993.

(9) Abdulhamid, M. A.; Park, S.-H.; Vovusha, H.; Akhtar, F. H.; Ng, K. C.; Schwingenschlögl, U.; Szekely, G. Molecular engineering of high-performance nanofiltration membranes from intrinsically microporous poly(ether-ether-ketone). J. Mater. Chem. A 2020, 8, 2444524454.

(10) Geyer, R.; Jambeck, J. R.; Law, K. L. Production, use, and fate of all plastics ever made. Sci. Adv. 2017, 3, No. e1700782.

(11) Chamas, A.; Moon, H.; Zheng, J.; Qiu, Y.; Tabassum, T.; Jang, J. H.; Abu-Omar, M.; Scott, S. L.; Suh, S. Degradation Rates of Plastics in the Environment. ACS Sustainable Chem. Eng. 2020, 8, 3494-3511.

(12) Morganti, P.; Yudin, V. E.; Morganti, G.; Coltelli, M.-B. Trends in Surgical and Beauty Masks for a Cleaner Environment. Cosmetics 2020, 7, No. 68 .

(13) Sharma, V. P. Polymers and Microplastics: Implications on Our Environment and Sustainability, Emerging Technologies, Environment and Research for Sustainable Aquaculture, IntechOpen Ltd: London, U.K., 2020.

(14) Wei, X.-F.; Nilsson, F.; Yin, H.; Hedenqvist, M. S. Microplastics Originating from Polymer Blends: An Emerging Threat? Environ. Sci. Technol. 2021, 55, 4190-4193.

(15) Alammar, A.; Hardian, R.; Szekely, G. Upcycling agricultural waste into membranes: from date seed biomass to oil and solventresistant nanofiltration. Green Chem. 2022, 24, 365-374.

(16) Razali, M.; Kim, J. F.; Attfield, M.; Budd, P. M.; Drioli, E.; Lee, Y. M.; Szekely, G. Sustainable wastewater treatment and recycling in membrane manufacturing. Green Chem. 2015, 17, 5196-5205.

(17) Nguyen Thi, H. Y.; Nguyen, B. T. D.; Kim, J. F. Sustainable Fabrication of Organic Solvent Nanofiltration Membranes. Membranes 2021, 11, No. 19.

(18) Zou, D.; Nunes, S. P.; Vankelecom, I. F. J.; Figoli, A.; Lee, Y. M. Recent advances in polymer membranes employing non-toxic solvents and materials. Green Chem. 2021, 23, 9815-9843.

(19) Fang, Z.; Zhang, H.; Qiu, S.; Kuang, Y.; Zhou, J.; Lan, Y.; Sun, C.; Li, G.; Gong, S.; Ma, Z. Versatile Wood Cellulose for Biodegradable Electronics. Adv. Mater. Technol. 2021, 6, No. 2000928.

(20) Falca, G.; Musteata, V.-E.; Behzad, A. R.; Chisca, S.; Nunes, S. P. Cellulose hollow fibers for organic resistant nanofiltration. J. Membr. Sci. 2019, 586, 151-161.

(21) Ghasemi, M.; Tsianou, M.; Alexandridis, P. Assessment of solvents for cellulose dissolution. Bioresour. Technol. 2017, 228, 330338.

(22) Rosenau, T.; Potthast, A.; Sixta, H.; Kosma, P. The chemistry of side reactions and byproduct formation in the system NMMO/ cellulose (Lyocell process). Prog. Polym. Sci. 2001, 26, 1763-1837.

(23) Barbosa, R. F. S.; Souza, A. G.; Maltez, H. F.; Rosa, D. S. Chromium removal from contaminated wastewaters using biodegradable membranes containing cellulose nanostructures. Chem. Eng. J. 2020, 395, No. 125055.

(24) Sayyed, A. J.; Mohite, L. V.; Deshmukh, N. A.; Pinjari, D. V. Structural characterization of cellulose pulp in aqueous NMMO solution under the process conditions of lyocell slurry. Carbohydr. Polym. 2019, 206, 220-228.

(25) Ilyin, S. O.; Makarova, V. V.; Anokhina, T. S.; Ignatenko, V. Y.; Brantseva, T. V.; Volkov, A. V.; Antonov, S. V. Diffusion and phase separation at the morphology formation of cellulose membranes by regeneration from $\mathrm{N}$-methylmorpholine $\mathrm{N}$-oxide solutions. Cellulose 2018, 25, 2515-2530.

(26) Ilyin, S. O.; Makarova, V. V.; Anokhina, T. S.; Volkov, A. V.; Antonov, S. V. Effect of coagulating agent viscosity on the kinetics of formation, morphology, and transport properties of cellulose nanofiltration membranes. Polym. Sci., Ser. A 2017, 59, 676-684.

(27) Anokhina, T. S.; Yushkin, A. A.; Makarov, I. S.; Ignatenko, V. Y.; Kostyuk, A. V.; Antonov, S. V.; Volkov, A. V. Cellulose composite 
membranes for nanofiltration of aprotic solvents. Pet. Chem. 2016, 56, $1085-1092$.

(28) Prézélus, F.; Chabni, D.; Barna, L.; Guigui, C.; Remigy, J.-C. A metrics-based approach to preparing sustainable membranes: application to ultrafiltration. Green Chem. 2019, 21, 4457-4469.

(29) Figoli, A.; Marino, T.; Simone, S.; Di Nicolò, E.; Li, X. M.; He, T.; Tornaghi, S.; Drioli, E. Towards non-toxic solvents for membrane preparation: a review. Green Chem. 2014, 16, 4034-4059.

(30) Jung, J. T.; Wang, H. H.; Kim, J. F.; Lee, J.; Kim, J. S.; Drioli, E.; Lee, Y. M. Tailoring nonsolvent-thermally induced phase separation (N-TIPS) effect using triple spinneret to fabricate high performance PVDF hollow fiber membranes. J. Membr. Sci. 2018, 559, 117-126.

(31) Cseri, L.; Szekely, G. Towards cleaner PolarClean: efficient synthesis and extended applications of the polar aprotic solvent methyl 5-(dimethylamino)-2-methyl-5-oxopentanoate. Green Chem. 2019, 21, 4178-4188.

(32) Marino, T.; Blasi, E.; Tornaghi, S.; Di Nicolò, E.; Figoli, A. Polyethersulfone membranes prepared with Rhodiasolv Polarclean as water soluble green solvent. J. Membr. Sci. 2018, 549, 192-204.

(33) Camp, J. E.; Nyamini, S. B.; Scott, F. J. Cyrene is a green alternative to DMSO as a solvent for antibacterial drug discovery against ESKAPE pathogens. RSC Med. Chem. 2020, 11, 111-117.

(34) Marino, T.; Galiano, F.; Molino, A.; Figoli, A. New frontiers in sustainable membrane preparation: Cyrene as green bioderived solvent. J. Membr. Sci. 2019, 580, 224-234.

(35) Dong, X.; Jeong, T. J.; Kline, E.; Banks, L.; Grulke, E.; Harris, T.; Escobar, I. C. Eco-friendly solvents and their mixture for the fabrication of polysulfone ultrafiltration membranes: An investigation of doctor blade and slot die casting methods. J. Membr. Sci. 2020, 614, No. 118510.

(36) Fadhil, S.; Marino, T.; Makki, H. F.; Alsalhy, Q. F.; Blefari, S.; Macedonio, F.; Nicolò, E. D.; Giorno, L.; Drioli, E.; Figoli, A. Novel PVDF-HFP flat sheet membranes prepared by triethyl phosphate (TEP) solvent for direct contact membrane distillation. Chem. Eng. Process. 2016, 102, 16-26.

(37) Livazovic, S.; Li, Z.; Behzad, A. R.; Peinemann, K. V.; Nunes, S. P. Cellulose multilayer membranes manufacture with ionic liquid. J. Membr. Sci. 2015, 490, 282-293.

(38) Sukma, F. M.; Çulfaz-Emecen, P. Z. Cellulose membranes for organic solvent nanofiltration. J. Membr. Sci. 2018, 545, 329-336.

(39) Durmaz, E. N.; Zeynep Çulfaz-Emecen, P. Cellulose-based membranes via phase inversion using [EMIM]OAc-DMSO mixtures as solvent. Chem. Eng. Sci. 2018, 178, 93-103.

(40) Costa, S. P. F.; Azevedo, A. M. O.; Pinto, P. C. A. G.; Saraiva, M. L. M. F. S. Environmental Impact of Ionic Liquids: Recent Advances in (Eco)toxicology and (Bio)degradability. ChemSusChem 2017, 10, 2321-2347.

(41) Baaqel, H.; Díaz, I.; Tulus, V.; Chachuat, B.; Guillén-Gosálbez, G.; Hallett, J. P. Role of life-cycle externalities in the valuation of protic ionic liquids-a case study in biomass pretreatment solvents. Green Chem. 2020, 22, 3132-3140.

(42) Puspasari, T.; Akhtar, F. H.; Ogieglo, W.; Alharbi, O.; Peinemann, K.-V. High dehumidification performance of amorphous cellulose composite membranes prepared from trimethylsilyl cellulose. J. Mater. Chem. A 2018, 6, 9271-9279.

(43) Klemm, D.; Heublein, B.; Fink, H.-P.; Bohn, A. Cellulose: Fascinating Biopolymer and Sustainable Raw Material. Angew. Chem., Int. Ed. 2005, 44, 3358-3393.

(44) Liu, H.; Hsieh, Y.-L. Ultrafine fibrous cellulose membranes from electrospinning of cellulose acetate. J. Polym. Sci., Part B: Polym. Phys. 2002, 40, 2119-2129.

(45) He, X. Optimization of Deacetylation Process for Regenerated Cellulose Hollow Fiber Membranes. Int. J. Polym. Sci. 2017, 2017, No. 3125413.

(46) Kim, J. F.; Gaffney, P. R. J.; Valtcheva, I. B.; Williams, G.; Buswell, A. M.; Anson, M. S.; Livingston, A. G. Organic Solvent Nanofiltration (OSN): A New Technology Platform for Liquid-Phase Oligonucleotide Synthesis (LPOS). Org. Process Res. Dev. 2016, 20, $1439-1452$
(47) Bryan, M. C.; Dunn, P. J.; Entwistle, D.; Gallou, F.; Koenig, S. G.; Hayler, J. D.; Hickey, M. R.; Hughes, S.; Kopach, M. E.; Moine, G.; Richardson, P.; Roschangar, F.; Steven, A.; Weiberth, F. J. Key Green Chemistry research areas from a pharmaceutical manufacturers' perspective revisited. Green Chem. 2018, 20, 5082-5103.

(48) Tian, Y.; Wu, M.; Liu, R.; Li, Y.; Wang, D.; Tan, J.; Wu, R.; Huang, Y. Electrospun membrane of cellulose acetate for heavy metal ion adsorption in water treatment. Carbohydr. Polym. 2011, 83, 743748.

(49) Wei, L.; Tan, W.; Wang, G.; Li, Q.; Dong, F.; Guo, Z. The antioxidant and antifungal activity of chitosan derivatives bearing Schiff bases and quaternary ammonium salts. Carbohydr. Polym. 2019, 226, No. 115256.

(50) Wolfs, J.; Meier, M. A. R. A more sustainable synthesis approach for cellulose acetate using the $\mathrm{DBU} / \mathrm{CO} 2$ switchable solvent system. Green Chem. 2021, 23, 4410-4420.

(51) Sun, J.; Cheng, W.; Yang, Z.; Wang, J.; Xu, T.; Xin, J.; Zhang, S. Superbase/cellulose: an environmentally benign catalyst for chemical fixation of carbon dioxide into cyclic carbonates. Green Chem. 2014, 16, 3071-3078.

(52) Antal, M. J., Jr.; Varhegyi, G. Cellulose Pyrolysis Kinetics: The Current State of Knowledge. Ind. Eng. Chem. Res. 1995, 34, 703-717.

(53) Huang, S.; Zhou, L.; Li, M.-C.; Wu, Q.; Zhou, D. Cellulose Nanocrystals (CNCs) from Corn Stalk: Activation Energy Analysis. Materials 2017, 10, No. 80.

(54) Kawamoto, H.; Murayama, M.; Saka, S. Pyrolysis behavior of levoglucosan as an intermediate in cellulose pyrolysis: polymerization into polysaccharide as a key reaction to carbonized product formation. J. Wood Sci. 2003, 49, 469-473.

(55) Lindstrom, J. K.; Proano-Aviles, J.; Johnston, P. A.; Peterson, C. A.; Stansell, J. S.; Brown, R. C. Competing reactions limit levoglucosan yield during fast pyrolysis of cellulose. Green Chem. 2019, 21, 178-186.

(56) Erdmann, R.; Kabasci, S.; Heim, H.-P. Thermal Properties of Plasticized Cellulose Acetate and Its $\beta$-Relaxation Phenomenon. Polymers 2021, 13, No. 1356.

(57) Tatsuko Hatakeyama, H. H. Thermal Properties of Cellulose and its Derivatives. In Thermal Properties of Green Polymers and Biocomposites; Springer Netherlands: Dordrecht, 2004; pp 39-130.

(58) Trilokesh, C.; Uppuluri, K. B. Isolation and characterization of cellulose nanocrystals from jackfruit peel. Sci. Rep. 2019, 9, No. 16709.

(59) Wei, Y.; Wang, Y.; Wang, L.; Yang, H.; Jin, H.; Lu, P.; Li, Y. Simultaneous phase-inversion and crosslinking in organic coagulation bath to prepare organic solvent forward osmosis membranes. J. Membr. Sci. 2021, 620, No. 118829.

(60) Vanherck, K.; Cano-Odena, A.; Koeckelberghs, G.; Dedroog, T.; Vankelecom, I. A simplified diamine crosslinking method for PI nanofiltration membranes. J. Membr. Sci. 2010, 353, 135-143.

(61) Valtcheva, I. B.; Marchetti, P.; Livingston, A. G. Crosslinked polybenzimidazole membranes for organic solvent nanofiltration (OSN): Analysis of crosslinking reaction mechanism and effects of reaction parameters. J. Membr. Sci. 2015, 493, 568-579.

(62) Zyaie, J.; Sheikhi, M.; Baniasadi, J.; Sahebi, S.; Mohammadi, T. Assessment of a Thermally Modified Cellulose Acetate ForwardOsmosis Membrane Using Response Surface Methodology. Chem. Eng. Technol. 2018, 41, 1706-1715.

(63) Gong, J.; Li, J.; Xu, J.; Xiang, Z.; Mo, L. Research on cellulose nanocrystals produced from cellulose sources with various polymorphs. RSC Adv. 2017, 7, 33486-33493.

(64) Karan, S.; Jiang, Z.; Livingston, A. G. Sub-10 nm polyamide nanofilms with ultrafast solvent transport for molecular separation. Science 2015, 348, 1347-1351.

(65) Hoarfrost, M. L.; Tyagi, M. S.; Segalman, R. A.; Reimer, J. A. Effect of Confinement on Proton Transport Mechanisms in Block Copolymer/Ionic Liquid Membranes. Macromolecules 2012, 45, $3112-3120$

(66) Gileadi, E.; Kirowa-Eisner, E. Electrolytic conductivity-the hopping mechanism of the proton and beyond. Electrochim. Acta 2006, 51, 6003-6011. 
(67) Li, Y.; Wang, S.; He, G.; Wu, H.; Pan, F.; Jiang, Z. Facilitated transport of small molecules and ions for energy-efficient membranes. Chem. Soc. Rev. 2015, 44, 103-118.

(68) Volkov, A.; Yushkin, A.; Kachula, Y.; Khotimsky, V.; Volkov, V. Application of negative retention in organic solvent nanofiltration for solutes fractionation. Sep. Purif. Technol. 2014, 124, 43-48.

(69) Soltane, H. B.; Roizard, D.; Favre, E. Study of the rejection of various solutes in OSN by a composite polydimethylsiloxane membrane: Investigation of the role of solute affinity. Sep. Purif. Technol. 2016, 161, 193-201.

(70) Kim, J. H.; Cook, M.; Peeva, L.; Yeo, J.; Bolton, L. W.; Lee, Y. M.; Livingston, A. G. Low energy intensity production of fuel-grade bio-butanol enabled by membrane-based extraction. Energy Environ. Sci. 2020, 13, 4862-4871.

(71) Lipnizki, F.; Hausmanns, S.; Ten, P.-K.; Field, R. W.; Laufenberg, G. Organophilic pervaporation: prospects and performance. Chem. Eng. J. 1999, 73, 113-129.

(72) Silvestre, W. P.; Baldasso, C.; Tessaro, I. C. Potential of chitosan-based membranes for the separation of essential oil components by target-organophilic pervaporation. Carbohydr. Polym. 2020, 247, No. 116676.

(73) Béguin, P.; Aubert, J.-P. The biological degradation of cellulose. FEMS Microbiol. Rev. 1994, 13, 25-58.

(74) Abdellah, M. H.; Pérez-Manríquez, L.; Puspasari, T.; Scholes, C. A.; Kentish, S. E.; Peinemann, K.-V. A catechin/cellulose composite membrane for organic solvent nanofiltration. J. Membr. Sci. 2018, 567, 139-145.

(75) Weng, R.; Huang, X.; Liao, D.; Xu, S.; Peng, L.; Liu, X. A novel cellulose/chitosan composite nanofiltration membrane prepared with piperazine and trimesoyl chloride by interfacial polymerization. RSC Adv. 2020, 10, 1309-1318.

(76) Varanasi, S.; Low, Z.-X.; Batchelor, W. Cellulose nanofibre composite membranes - Biodegradable and recyclable UF membranes. Chem. Eng. J. 2015, 265, 138-146.

(77) Morgado, D. L.; Frollini, E. Thermal decomposition of mercerized linter cellulose and its acetates obtained from a homogeneous reaction. Polimeros 2011, 21, 111-117.

(78) Puspasari, T.; Peinemann, K.-V. Application of thin film cellulose composite membrane for dye wastewater reuse. J. Water Process Eng. 2016, 13, 176-182.

(79) Puspasari, T.; Yu, H.; Peinemann, K.-V. Charge- and SizeSelective Molecular Separation using Ultrathin Cellulose Membranes. ChemSusChem 2016, 9, 2908-2911.

(80) Puspasari, T.; Chakrabarty, T.; Genduso, G.; Peinemann, K.-V. Unique cellulose/polydimethylsiloxane blends as an advanced hybrid material for organic solvent nanofiltration and pervaporation membranes. J. Mater. Chem. A 2018, 6, 13685-13695.

(81) Puspasari, T.; Huang, T.; Sutisna, B.; Peinemann, K.-V. Cellulose-polyethyleneimine blend membranes with anomalous nanofiltration performance. J. Membr. Sci. 2018, 564, 97-105.

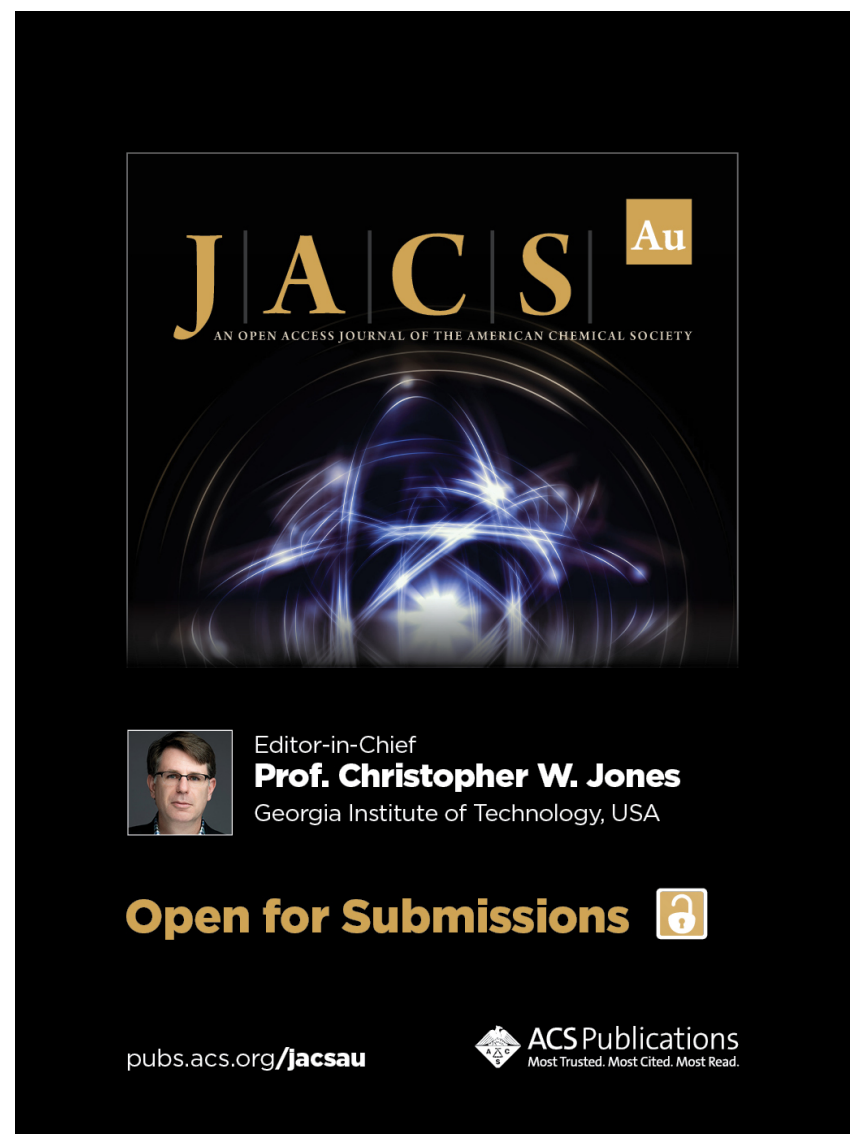

